\title{
Maturation of the Contractile Response and Its Endothelial Modulation in Newborn Porcine Intrapulmonary Arteries
}

\author{
MARILYNE LEVY, ROBERT M. R. TULLOH, ${ }^{1}$ HIROYOSHI KOMAI, KAREN STUART-SMITH, \\ AND SHEILA G. HAWORTH \\ Developmental Vascular Biology and Pharmacology Unit, the Institute of Child Health, London WC1N \\ IEH, United Kingdom
}

\begin{abstract}
ABS
Pulmonary vascular reactivity is thought to be greater in the newborn than adult lung. To determine the influence of the endothelium on smooth muscle cell contractility, responses of rings of isolated intrapulmonary arteries were studied from pigs at birth aged $<2 \mathrm{~h}, 2 \mathrm{~d}, 3 \mathrm{~d}$, and $10 \mathrm{~d}$ ( $n=4$ per age group) and from eight adult animals. At birth, the response to $\mathrm{KCl}(25 \mathrm{mM})$ and prostaglandin $\mathrm{F}_{2 \alpha}\left(\mathrm{PGF}_{2 \alpha}\right)(3 \mu \mathrm{M})$ but not histamine $(0.1$ $\mathrm{mM}$ ) was gxeater in rings with endothelium $(\mathrm{E}+)$ than without $\left(\mathrm{E}-\right.$ ). The response to $\mathrm{PGF}_{2 \alpha}$ decreased between birth and $3 \mathrm{~d}$ by which time the contraction was less in $\mathrm{E}+$ rings than $\mathrm{E}-$, but L-nitro monomethyl arginine augmented contraction at all ages. In the immature piglets, the response to phenylephrine was less in $\mathrm{E}+$ rings than $\mathrm{E}-$, an effect which was reversed by $\mathrm{L}-N^{\omega}$ nitro-L-arginine methyl ester. The response to all contractile agonists increased between $10 \mathrm{~d}$ and adulthood. The concentration of plasma endothelin-1 was determined in all animals by RIA and was higher at birth than at $3 \mathrm{~d}$ or later. In summary, $l$ )
\end{abstract}

at birth, endothelium enhanced contractility, when plasma endothelin was greatest, but released NO in the presence of phenylephrine and $\mathrm{PGF}_{2 \alpha} ; 2$ ) contractile response to all agonists was small at birth; and 3) a complex interaction existed between the contractile agonist and the effect of endothelial maturation. This study suggests that excessive reactivity in the newborn pulmonary vasculature may be due to immaturity of mechanisms determining endothelium-dependent arterial relaxation, but not to an excessive contractile response. (Pediatr Res 38: 25-29, 1995)

PGF $_{2 \alpha}$, prostaglandin $\mathrm{F}_{2 \alpha}$

PE, phenylephrine

L-NAME, $N^{\omega}$-nitro-L-arginine methyl ester

L-NMMA, L-nitro monomethyl arginine

EDRF, endothelium-derived relaxing factor

NO, nitric oxide
At birth, the pulmonary arterial pressure and resistance are high and decrease rapidly during the first hours after birth due to structural $(1-3)$ and functional $(4,5)$ remodeling. The mechanisms responsible for these changes are not fully elucidated, but EDRF is known to play a role. EDRF (6-8) is released from the lungs of fetal and newborn animals (9-11). It helps reduce basal tone in utero and contributes to the postnatal fall in pulmonary vascular resistance. However, endothelium-dependent relaxation to acetylcholine is absent at birth in the porcine lung and does not appear until the third day of life (5). In the ovine lung, endothelial-dependent relaxation in response to acetylcholine, $\mathrm{ADP}$, and calcium ionophore (A23187) is minimal in utero and at birth and increases rapidly during the first week of life (12). These observations suggest that immediately after birth the interactions between the endo-

Received July 14, 1994; accepted January 26, 1995.

Correspondence: Prof. S. G. Haworth, Developmental Vascular Biology and Pharmacology Unit, Institute of Child Health, 30 Guilford Street, London WC1N 1EH, UK.

Supported by the British Heart Foundation.

${ }^{1}$ British Heart Foundation Junior Research Fellow. thelium and the underlying smooth muscle may be different from those in adult porcine pulmonary vasculature. In mature blood vessels, the endothelium is thought to play an important role in the control of vascular tone through a balance between EDRF such as NO (10), prostacyclin (13), bradykinin (14), the endothelium-derived hyperpolarizing factor (15), and the endothelium-derived contracting factors, such as endothelin (16) and thromboxane $A_{2}$ (17).

The present study investigates the influence of the endothelium on the contractile responses of isolated porcine intrapulmonary vessels taken from the newborn (less than $2 \mathrm{~h}$ ), from animals aged 2, 3, and $10 \mathrm{~d}$ and from adult animals.

\section{METHODS}

The isolated intrapulmonary arteries of eight adult large white pigs $(n=8)$ and 16 piglets aged less than $2 \mathrm{~h}(n=4)$, $2 \mathrm{~d}(n=4), 3 \mathrm{~d}(n=4)$, and $10 \mathrm{~d}(n=4)$ were studied. The piglets were taken from four sows. Animals received humane care in compliance with the "Principles of Laboratory Animal 
Care" formulated by the National Society of Medical Research and the "Guide for the Care and Use of Laboratory Animals" prepared by the National Academy of Science and published by the National Institutes of Health (National Institutes of Health Publication No. 80-23, revised 1978). The piglets were delivered normally and killed by exsanguination after being anesthetized with sodium pentobarbitone $(100 \mathrm{mg} / \mathrm{kg})$. The heart and lungs were removed en bloc and placed in cold Krebs-Ringer bicarbonate solution of the following composition (in $\mathrm{mM}$ ): $\mathrm{NaCl} 118.3, \mathrm{KCl} 4.7, \mathrm{CaCl}_{2} 2.5, \mathrm{MgSO}_{4} 1.2$, $\mathrm{KH}_{2} \mathrm{PO}_{4} 1.2, \mathrm{NaHCO}_{3} 25$, glucose 11.1. The distal portion of the muscular intrapulmonary arteries was dissected free from the surrounding lung parenchyma and cut into rings (2.5-3-mm length) taking care not to touch the luminal surface. Care was taken to obtain the rings from the equivalent portion of artery at each age. The external diameter therefore ranged from $2 \mathrm{~mm}$ in the neonate to $3.5 \mathrm{~mm}$ in the adult. These were the arteries accompanying the larger bronchioles. In some rings, the endothelium was removed by gently rubbing the luminal surface with watchmaker's forceps. A total of six to eight rings was taken from each animal.

Each ring was then suspended in a $5-\mathrm{mL}$ organ bath filled with Krebs solution at $37^{\circ} \mathrm{C}$, gassed with $95 \% \mathrm{O}_{2}$ and $5 \% \mathrm{CO}_{2}$, and attached to a Grass FTO3 transducer. Isometric forces were recorded on a model 7 Grass polygraph. Each ring was stretched progressively and exposed to two conditioning doses of $\mathrm{KCl}(25 \mathrm{mM})$. The rings were incubated with indomethacin $(10 \mu \mathrm{M})$ and allowed to equilibrate for $60 \mathrm{~min}$.

Pharmacologic protocols. To compare the influence of the endothelium on the smooth muscle responses to contractile agonists, rings with and without endothelium were first exposed to $\mathrm{KCl}(25 \mathrm{mM})$ at all ages as previously reported from our laboratory (5) and then were exposed to $\operatorname{PGF}_{2 \alpha}(3 \mu \mathrm{M})$. This latter concentration was chosen because previous experiments in our laboratory had shown that it produces reproducible, consistent contractions at all ages, and in fact this concentration represents the $\mathrm{EC}_{30}$ (18). If a higher concentration was used, it was not possible to wash out the drug effectively. Endothelial function was confirmed by the relaxant response to acetylcholine in rings taken from animals more than $2 \mathrm{~d}$ old. The rings were then washed until baseline tone was regained, again incubated for $30 \mathrm{~min}$ with indomethacin and then exposed to either histamine $(0.1 \mathrm{mM})$ or to $\mathrm{PE}(0.1 \mathrm{mM})$. Previous experiments from our laboratory confirmed that these concentrations cause maximal contractile responses to these agonists (19). In a parallel, simultaneous series of experiments, rings were exposed to either histamine, $\mathrm{PGF}_{2 \alpha}$, or $\mathrm{PE}$ and a nitric oxide synthase inhibitor, either L-NAME $(3 \mu \mathrm{M})$ or L-NMMA $(30 \mu \mathrm{M})$. These agents were used to assess the role of nitric oxide production in endothelium-dependent differences in contractile responses to these agonists, at each age. All rings were exposed to sodium nitroprusside $(0.1 \mathrm{mM})$ to confirm the capacity of the smooth muscle to relax. Last, all the rings were blotted on filter paper and weighed.

Histology. At the end of each experiment, all of the rings were prepared as for electron microscopy, fixed in glutaraldehyde, embedded in Araldite, cut in thin $1-\mu \mathrm{m}$ sections, and stained with toluidine blue to confirm the presence or absence of endothelium as appropriate.

Drugs. The following drugs were used: histamine dihydrochloride, indomethacin, phenylephrine, L-NAME, ¿-NMMA, potassium chloride, $\mathrm{PGF}_{2 \alpha}$, sodium nitroprusside (all from Sigma Chemical Co., Poole, UK). The indomethacin was dissolved in distilled water with $\mathrm{Na}_{2} \mathrm{CO}_{3}(10 \mu \mathrm{M})$. All drug concentrations are expressed as the final molar concentration in the organ bath solution.

Data analysis. The tension generated in response to each agonist was expressed in grams per mg of wet weight. For each animal, six to eight rings were studied, with and without endothelium, and $n$ represents the number of rings tested. All of the data are expressed as mean \pm SD. Statistical analysis was performed on paired or unpaired rings (rings with and without endothelium and before and after L-NAME on the same ring) using the $t$ test. To compare rings from animals of different age groups, an analysis of variance confirmed with the Bonferroni-corrected $t$ test was used. Values were considered statistically significant when $p<0.05$.

Plasma level of endothelin-1. Blood samples were taken from the same pigs as those used for the organ bath experiments, aged less than $2 \mathrm{~h}(n=4), 3 \mathrm{~d}(n=3), 10 \mathrm{~d}(n=2)$, and adults $(n=4)$. Endothelin-1 was measured by a RIA technique using a MAb specific for endothelin-1-21 (Radioimmunoassay Kit, Amersham, UK). The cross reactivities of the antibody are $100 \%$ for endothelin-1, $14.4 \%$ for endothelin-2, $52 \%$ for endothelin-3, and $0.4 \%$ for big endothelin- 1 . The concentration of endothelin-1 is expressed in picomoles/ liter. A $t$ test was used to compare the plasma concentration of endothelin-1 at different ages.

\section{RESULTS}

For each vessel studied, examination of the 1- $\mu \mathrm{m}$ sections confirmed the presence or absence of endothelium, as appropriate. This included the newborns and the 2-d-old animals, in which acetylcholine did not initiate a relaxation in arteries with endothelium. All rings from the same animals and from those of the same age responded in a similar manner, except where stated, and therefore the data were pooled. All rings relaxed completely to sodium nitroprusside.

The response to $\mathrm{KCl}$ (Fig. IA). In rings with endothelium, the contractile response to $\mathrm{KCl}$ did not change during the first $10 \mathrm{~d}$ of life but then increased significantly between $10 \mathrm{~d}$ and adulthood $(p<0.05)$. In rings without endothelium, the tone induced by $\mathrm{KCl}$ increased significantly between $2 \mathrm{~d}$ and adulthood ( $p<0.01$ ). Rings with endothelium showed a significantly greater contractile response at birth than those without endothelium $(p<0.05)$. By contrast, rings with endothelium showed a significantly smaller contractile response in adulthood than those without endothelium $(p<0.05)$.

The response to $P G F_{2 \alpha}$ (Fig. $1 B$ ). In rings with endothelium, the contraction was greater at birth than at either 2 or 3 $\mathrm{d}(p<0.01$ for each comparison). It then increased between 10 $\mathrm{d}$ and adulthood $(p<0.01)$. By contrast, the magnitude of the contractile response to $\mathrm{PGF}_{2 \alpha}$ in rings without endothelium did not change significantly between birth and $10 \mathrm{~d}$ of age. It then 

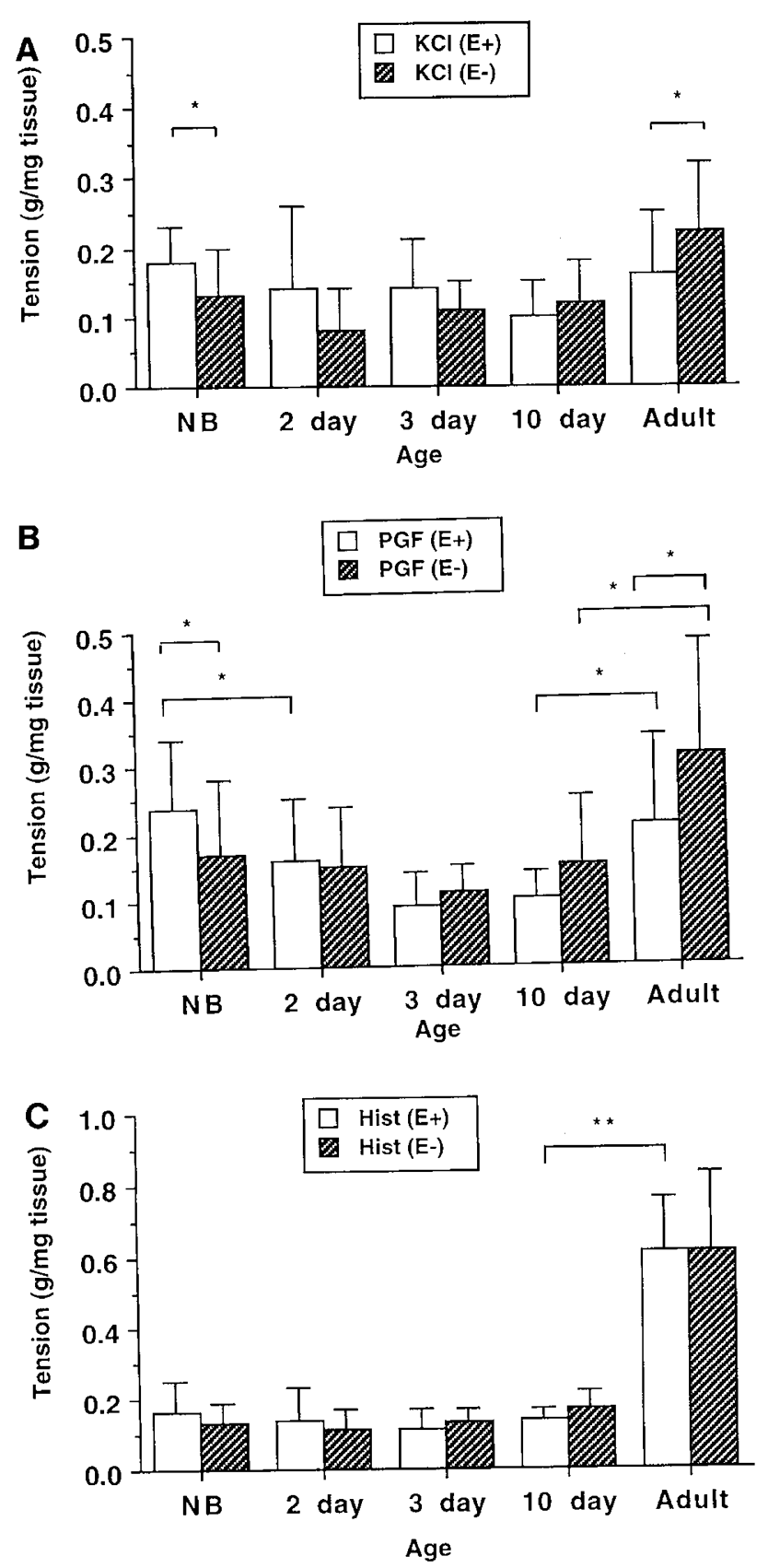

Figure 1. Contractile response at different ages. Contractile response as grams of tension per $\mathrm{mg}$ of tissue in arteries with $(E+)$ and without $(E-)$ endothelium in response to: $I) \mathrm{KCl}, 2) \mathrm{PGF}_{2 \alpha}$, and 3) histamine. $N B=$ newborn less than $2 \mathrm{~h}$ old. Mean \pm SD of data from each of four piglets at each age and from eight adults $* p<0.05$.

increased significantly between $10 \mathrm{~d}$ and adulthood $(p<0.01)$. In the newborn, the contractile response to $\mathrm{PGF}_{2 \alpha}$ was greater in rings with than without endothelium $(p<0.05)$. By contrast, there was no significant difference in the amount of tone generated between arteries with and without endothelium at 2 , 3 , and $10 \mathrm{~d}$. In adults, the contractile response induced by $\mathrm{PGF}_{2 \alpha}$ was less in tissues with than without endothelium $(p<$ $0.01)$. The addition of L-NMMA caused a significant increase in contraction in rings with endothelium ( $p<0.05$ at all ages), although the increase was greatest at $10 \mathrm{~d}$ of age $(29 \pm 4 \%$ at birth, $37 \pm 12 \%$ at 2 or $3 \mathrm{~d}, 63 \pm 10 \%$ at $10 \mathrm{~d}$, and $50 \pm 18 \%$ at adulthood, expressed as percent of the precontraction. $p<$ 0.05 comparing the response at birth with that in the adult). There was a small increase in resting tension in the presence of L-NMMA (expressed as a percentage of the preceding $\mathrm{KCl}$ contraction in each case, increasing from $7 \pm 5 \%$ at birth to 33 $\pm 11 \%$ at $17 \mathrm{~d}$ ).

The response to histamine (Fig. $1 C$ ). In rings with endothelium the contractile response appeared to decrease between birth and $3 \mathrm{~d}$, although the change was not statistically significant, but then increased significantly between $10 \mathrm{~d}$ and adulthood $(p<0.001)$. In rings without endothelium the response did not change between birth and $10 \mathrm{~d}$ of age but again showed a considerable increase to that seen at adulthood $(p<0.001)$. Addition of L-NAME did not alter the response to histamine at any age.

The response to phenylephrine (Fig. $2 A$ ). The contractile response to $\mathrm{PE}$ in arteries with and without endothelium was poor during the first $3 \mathrm{~d}$ of life. In the newborn, rings from only one out of four animals responded to PE. In the 2- and 3-d-old animals, the response was variable with some rings showing a small contraction and others showing no response. In those rings that did respond to $\mathrm{PE}$ at these ages, the response was less in rings with than without endothelium $(p<0.01)$. Rings from all 10-d-old animals contracted and again the response was significantly less in the presence of endothelium $(p<0.01)$. Rings from adult animals showed a greater response to PE compared with that seen in all the younger age groups $(p<$
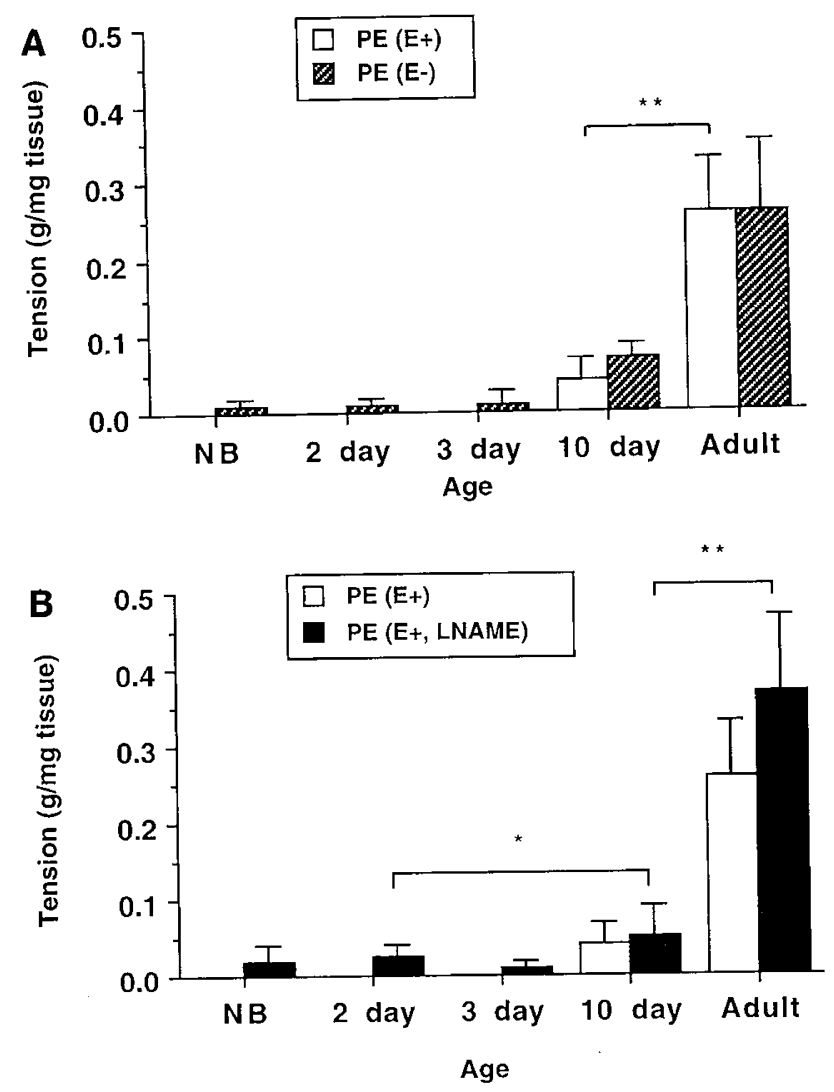

Figure 2. Contractile response to PE. Contractile response of arteries with endothelium to PE at different ages in the absence $(A)$ and presence $(B)$ of L-NAME. $N B=$ newborn less than $2 \mathrm{~h}$ old. Mean $\pm \mathrm{SD}$ of data from each of four piglets at each age and from eight adults, ${ }^{*} p<0.05$. 
0.001 for rings both with and without endothelium). No difference was observed between rings with and without endothelium.

Addition of L-NAME significantly enhanced the response to $\mathrm{PE}$ in rings with endothelium from newborn and 2-d-old animals and in four rings elicited a response in rings in which a contraction had not previously been detected (Fig. 2B). In rings from adult animals there was a significant increase in contractile response in the presence of L-NAME $(p<0.05)$.

Endothelin-1 plasma levels (Fig. 3). The plasma endothelin level at $10 \mathrm{~d}$ was similar to that seen in the adult and therefore the data from all these animals were pooled. In the newborn, the plasma level of endothelin-1 was significantly greater than in any other age group ( $p<0.01$ compared with $3 \mathrm{~d}, p<0.05$ compared with adults). There was no difference in endothelin-1 level between $3 \mathrm{~d}$ and adulthood.

\section{DISCUSSION}

In this study on the normal newborn pulmonary vasculature, we found that in isolated pulmonary arterial rings without endothelium the contractile response to all agonists investigated, $\mathrm{KCl}$ and $\mathrm{PGF}_{2 \alpha}$, histamine and phenylephrine, increased between birth and adulthood. The effect of the endothelium upon contractility varied with age and depended also on the contractile agonist used. The endothelium augmented the contractile response to $\mathrm{KCl}$ and $\mathrm{PGF}_{2 \alpha}$ at birth and inhibited it from $10 \mathrm{~d}$ onward. The endothelium appeared to have a similar effect on histamine induced contractility during the first $10 \mathrm{~d}$, but the changes were small and not statistically significant. By contrast, the presence of endothelium reduced the contractile response to phenylephrine during the first $10 \mathrm{~d}$ of life, but made no difference to the response in adult vessels. We investigated the possible role of NO in these endothelial dependent responses and found that an NO synthase inhibitor augmented the contractile response to $\mathrm{PGF}_{2 \alpha}$ and $\mathrm{PE}$ at all ages. L-NMMA caused a small but significant contraction at resting tension, again at all ages. For both $\mathrm{PGF}_{2 \alpha}$ and PE, the effect tended to be less in arteries from immature rather than adult animals. Thus, the present study demonstrated complex changes in the functional properties of both pulmonary arterial endothelial and smooth muscle cells, and in the interaction between these

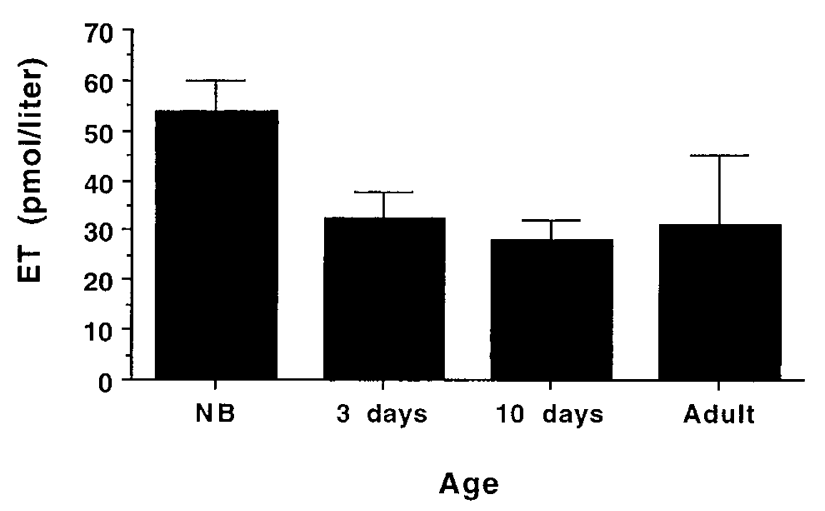

Figure 3. Plasma level of endothelin-1 (ET). Expressed in picomoles/liter in animals of different ages. $N B=$ newborn less than $2 \mathrm{~h}$ old. Mean $\pm \mathrm{SD}$ of four to eight animals at each age, ${ }^{*} p<0.05$. cell types during development. The problem of elucidating the changing relationships is made more difficult by our finding that the magnitude of the contractile response as well as the modulating effect of the endothelium depended not only on age, but on the contractile agonist used.

The contractile response of the rings from the younger animals to $\mathrm{KCl}$ and $\mathrm{PGF}_{2 \alpha}$ was enhanced by the presence of endothelium. It has been suggested that fetal pulmonary arterial endothelium releases a constricting factor, as yet unidentified. Possible candidates include arachidonic acid metabolites $(17,20)$, a possibility excluded in these studies by the presence of indomethacin, and endothelin. However, the physiologic effect of endothelin is complex and influenced by EDRF/NO $(21,22)$. That newborn pulmonary arteries contracting to $\mathrm{PGF}_{2 \alpha}$ were releasing EDRF/NO was shown by augmentation of the contractile responses in the presence of L-NMMA. NO has been shown to inhibit the release of endothelin- 1 by activation of endothelial endothelin- $\mathrm{T}_{\mathrm{B}}$ receptors. In the present study, the plasma endothelin level had fallen by $3 \mathrm{~d}$ of age, the time at which both the density of endothelin- $T_{B}$ receptors (23) and the amount of endothelial NO synthase increased (24). Functionally, at $3 \mathrm{~d}$ a vasodilator response to endothelin occurs in the isolated perfused porcine lung (21). Thus, the physiologic effect of endothelin may change in the first days of life and at birth may play a transitory role in mediating the contractile effect of the endothelium in pulmonary arteries exposed to $\mathrm{PGF}_{2 \alpha}$.

The response to each of the contractile agonists used in the present study increased between $10 \mathrm{~d}$ of age and adulthood. This increase in contractility was associated with an increase in the density of pulmonary arterial smooth muscle cell myofilaments (3). The most dramatic changes, however, occurred in response to the receptor mediated agonists histamine and $\mathrm{PE}$, suggesting that maturational changes in these receptors or their signal transduction mechanisms are also important in the maturation of the contractile response. The response to the $\alpha-1$ agonist PE was extremely poor during the first $10 \mathrm{~d}$ of life and other investigators have also noted a poor response to $\alpha$-agonists at this time (25). These findings could be due to a lower density of adrenoreceptors in young animals (26) and may also reflect immaturity of the receptors and their signal transduction processes. In the present study, the contractile response to the $\alpha-1$ agonist in arteries with endothelium was augmented by L-NAME at all ages, confirming work on adult rat perfused lung (27). This suggests that EDRF/NO was released in response to $\mathrm{PE}$ at birth, in a sufficient amount to suppress the poor contractile response to $\mathrm{PE}$. As with the response to $\mathrm{PE}$, the contractile response to histamine was poor in arteries from young animals, but unlike the response to PE, an NO synthase inhibitor had no significant effect on the contractile response. Although we found only a small, statistically insignificant endothelial dependent relaxation at 3 and $10 \mathrm{~d}$ of age, others have described endothelial-dependent relaxation to histamine in adult pulmonary arteries in the human (28) and in isolated perfused newborn lamb lungs, possibly mediated through the $\mathrm{H}-1$ receptor (29). These findings suggest that of the contractile agonists used, only histamine did not stimulate EDRF release in the porcine pulmonary arteries, or alternatively that EDRF 
was released but in too small an amount to modify even a weak contraction.

In summary, the findings of the present study reveal a complex relationship between the endothelial and smooth muscle cells in isolated pulmonary arteries of newborn pigs, a relationship which changes rapidly during the first days of life. The endothelium enhanced the contractile response at birth, possibly due to release of a constricting factor such as endothelin, and its customary relaxant effect appeared between the third and tenth days of life. Despite the predominantly constrictor effect of the endothelium at birth, the use of NO synthase inhibitors demonstrated the release of EDRF at this time, as have other studies (11). This EDRF may, however, be less effective than in adults because isolated newborn pulmonary arteries without endothelium are relatively insensitive to exogenous NO $(4,19)$. The contractile response of the smooth muscle cells to all agonists used in the present study was relatively small at birth. In conclusion, the findings suggest that the newborn predisposition to excessive reactivity and vasoconstriction may be due to immaturity of the mechanisms determining endothelium-dependent relaxation, rather than to an excessively vigorous contractile response. In addition, our study was confined to the intrapulmonary arteries, but both the microvasculature and venous segments may make significant, and changing contributions to total pulmonary vascular resistance in early life.

Acknowledgment. The authors thank Joan Deutsch for valuable technical assistance.

\section{REFERENCES}

1. Haworth SG, Hislop AA 1981 Adaptation of the pulmonary circulation to extrauterine life in the pig and its relevance to the human infant. Cardiovasc Res 15:108-119

2. Allen K, Haworth SG 1988 Human postnatal pulmonary arterial remodelling: Ultrastructural studies of smooth muscle cell and connective tissue maturation. Lab Invest 59:702-709

3. Hall S, Haworth SG 1986 Conducting pulmonary arteries: Structural adaptation to extra-uterine life. Cardiovasc Res 21:208-216

4. Zellers TM, Vanhoutte PM 1991 Endothelium-dependent relaxations of piglet pulmonary arteries augment with maturation. Pediatr Res 30:176-180

5. Liu S, Hislop AA, Haworth SG, Barnes PJ 1992 Developmental changes in endothelium-dependent pulmonary vasodilatation in pigs. Br J Pharmacol 106:324-330

6. Vanhoutte PM, Rubanyi GM, Miller VM, Houston DS 1986 Modulation of vascular smooth muscle contraction by the endothelium. Annu Rev Physiol 48:307-320

7. Martin W, Furchgott RF, Villani GM, Jothianandan D 1986 Depression of contractile responses in rat aorta by spontaneously released endothelium-derived relaxing factor. J Pharmacol Exp Ther 237:529-538
8. Crawley DE, Liu SF, Evans TW, Barnes PJ 1990 Inhibitory role of endotheliumderived relaxing factor in rat and human pulmonary arteries. $\mathrm{Br} \mathrm{J}$ Pharmacol 101:166-170

9. Tiktinsky MH, Cummings JJ, Morin FC III 1992 Acetylcholine increases pulmonary flow in intact fetuses via endothelium-dependent vasodilation. Am J Physiol 262:H406- $\mathrm{H} 410$

10. Chang JK, Moore P, Fineman JR, Soifer SJ, Heyman MA 1992 K+ channel pulmonary vasodilation in fetal lambs: role of endothelium-derived nitric oxide. $J$ Appl Physiol 73:188-194

11. Abman SH, Chatfield BA, Hall SL, McMurtry IF 1990 Role of endothelium-derived relaxing factor during transition of pulmonary circulation at birth. Am J Physiol 259:H1921-H1927

12. Abman SH, Chatfield BA, Rodman DM, Hall SL, McMurtry IF 1991 Maturational changes in endothelium-derived relaxing factor activity of ovine pulmonary arteries in vitro. Am J Physiol 260:L280-L285

13. Davidson D 1988 Pulmonary haemodynamics at birth: Effects of acute cyclooxygenase inhibition in lambs. J Appl Physiol 64:1676-1682

14. Altura BM, Chand N 1981 Bradykinin-induced relaxation of renal and pulmonary arteries is dependent upon intact endothelial cells. Br J Pharmacol 74:10-11

15. Chen GH, Suzuki H, Weston AH 1988 Acetylcholine releases endothelium-derived hyperpolarising factor and EDRF from rat blood vessels. Br J Pharmacol 95:11651174

16. Yanagisawa M, Kurihara H, Kimura S, Tomobe Y, Kobayashi M, Mitsui Y, Yazaki Y, Goto K, Masaki T 1988 A novel potent vasoconstrictor peptide produced by vascular endothelial cells. Nature 332:411-415

17. Hamberg M, Svensson J, Samuelsson B 1975 Thromboxanes: A new group of biologically active compounds derived from prostaglandin endoperoxides. Proc Nat Acad Sci USA 72:2994-2998

18. Tulloh RMR, Boels PJ, Hodgson PE, Haworth SG 1994 Chronic hypoxia alters contractile and relaxant responses in isolated intrapulmonary arteries of the newborn pig. Am J Respir Crit Care Med 149:A26

19. Wilson LE, Levy M, Stuart-Smith K, Haworth SG 1993 Postnatal adrenoreceptor maturation in porcine intrapulmonary arteries. Pediatr Res 34:591-595

20. Miller VM, Vanhoutte PM 1985 Endothelium-dependent contractions to arachidonic acid are mediated by products of cyclooxygenase. Am J Physiol 248:H432-H437

21. Tod ML, Cassin S 1992 Endothelin-1-induced pulmonary arterial dilation is reduced by $N$ - $\omega$-nitro-L-arginine in fetal lambs. J Appl Physiol 72:1730-1734

22. Wang Y, Coceani F 1992 Isolated pulmonary resistance vessels from fetal lambs: Contractile behaviour and response to indomethacin and endothelin-1. Circ Res $71: 320-330$

23. Hislop AA, Zhao YD, Springall DR, Polak JM, Haworth SG 1991 Endothelin binding (receptor) sites in the developing porcine pulmonary circulation. Am Rev Respir Dis 143:A404

24. Hislop AA, Buttery LKD, Springall DR, Pollock J, Polak JM, Haworth SG 1993 Localisation of pulmonary arterial endothelial nitric oxide synthase in neonatal pigs. Cardiol Young(3 suppl)1:A334

25. Dunn JA, Lorch V, Sinha SN 1989 Responses of small intra-pulmonary arteries to vasoactive compounds in the fetal and neonatal lamb: Norepinephrine, epinephrine, serotonin and potassium chloride. Pediatr Res 25:360-363

26. Shaul PW, Farrar MA, Buja LM 1991 Ontogeny of B-adrenergic regulation of adenylate cyclase in intrapulmonary arteries from fetal and postnatal lambs. Pediatr Res 30:610-615

27. Shaw A, MacLean MR, Pollock D, McGrath JC 1992 Influence of L-NAME on $\alpha-1$ and $\alpha-2$ adrenoceptor and responses in the isolated rabbit pulmonary artery and the rat Krebs-perfused lung. J Vasc Res 29:197

28. Ortiz JL, Labat C, Norel X, Gorenne I, Verley J, Brink C 1992 Histamine receptors on human isolated pulmonary arterial muscle preparation: Effects of endothelial cell removal and nitric oxide inhibitors. J Pharmacol Exp Ther 260:762-767

29. Gordon J, De Clety S, Chu K 1991 Developmental changes in vascular responses to histamine in normoxic and hypoxic lamb lungs. J Appl Physiol 70:323-330 